\title{
CERVICAL ECTOPIC PREGNANCY: A DIAGNOSTIC DILEMMA
}

\author{
Bhakti Gurjar¹, Mansi Shrigiriwar², Kshama Kedar³
}

\section{HOW TO CITE THIS ARTICLE:}

Bhakti Gurjar, Mansi Shrigiriwar, Kshama Kedar. "Cervical Ectopic Pregnancy: A diagnostic dilemma". Journal of Evolution of Medical and Dental Sciences 2015; Vol. 4, Issue 72, September 07; Page: 12621-12624,

DOI: $10.14260 /$ jemds/2015/1819

ABSTRACT: Cervical pregnancy is defined as implantation and development of the fertilized ovum within the cervical structure without involving the corpus uteri. This rare ectopic gestation has been reported in the literature infrequently. We report here a case presenting late with life threatening vaginal bleeding. G3 P2L2 with Previous two Caesarean sections with history of amenorrhea of 3 months presented to our emergency obstetric unit with heavy bleeding per-vaginum since one day. Patient gave history of having taken abortive pills from a private practitioner, details of which were not available. Differential diagnosis of cervical abortion and scar site pregnancy were considered. Ultrasound features can help diagnose this condition with fair accuracy. Ultimately an emergency salvage Hysterectomy was needed to save the life of the patient.

KEYWORDS: Cervical Ectopic Pregnancy.

INTRODUCTION: On 2/05/2015 at 12.30AM a 22 years old lady, G3 P2L2 with Previous two Caesarean sections with history of amenorrhea of 3 months came with chief complaint of bleeding per vaginum since 7/04/2015 (35 days) and history of passage of clots per vaginum since one day. Her LMP was on 11/02/2015. Patient gave history of having taken abortive pills from a private practitioner, details of which were not available. Her previous menstrual cycles were regular, of average flow and of 3-4 days duration. She was not using any contraception. Her first child was born by Caesarean section done for cephalopelvic disproportion 3 years back. Her second caesarean section was done 5 months back for same indication. Both of her children were alive and doing well. She had no significant medical or surgical history in the past. On examination her general condition was moderate. She was afebrile, but had tachycardia of about 120 beats per minute. She was severely pale and her BP was 90/60mm of Hg. Her Extremities were cold.

On per abdominal examination she had 14 weeks sized uterus while on speculum examination an open cervical os with profuse bleeding was seen. On bimanual pelvic examination Uterus was about 12 to 14 weeks in size, soft and tender. Os was open with products of conception filling the cervix and cervix was ballooned up.

After initial resuscitation, emergency ultrasound examination was done. On ultrasound examination Uterus was $11.0 \times 8.9 \times 7.0 \mathrm{~cm}$. Endometrial echoes were not seen. There was an illdefined heterogeneous lesion without any internal vascularity with peripheral vascularity seen with multiple cystic spaces seen within the endometrial canal and anterior part of uterine myometrium suggestive of scar site hematoma more likely than a molar pregnancy. Decision of emergency evacuation taken and she was shifted to OT. Under anesthesia Per Vaginum examination was done. Patient started bleeding profusely \& Became pulse less BP less.

A provisional diagnosis of scar rupture was made and decision for Emergency Exploratory Laparotomy. There was no Hemoperitonium, Uterus was bulky in size and ballooned up Cervix with densely adherent Bladder. There was no rent on Previous Scar Site. Provisional Diagnosis of Cervical 
Ectopic Pregnancy was made in view of 1). Normal to bulky uterus with enlarged cervix 2). Evidence of empty uterus on USG 3) No scar hematoma which was suspected on USG \& clinically.

Decision of Emergency Obstetric Hysterectomy was taken. Urinary Bladder was pulled up and firmly adherent over Cervix. Sharp dissection was done. Uterine vessels were visualized \& ligated. Accidental bladder injury occurred during dissection. Dissection was continued till vaginal vault was visible. Total Hysterectomy was done. Bladder repair was done in double layer. Three units of whole blood were transfused. Patient had an uneventful recovery. Urinary catheter was removed on day 14 and patient was doing well on visit at 6 weeks.

Histopathology proved beyond doubt a cervical ectopic pregnancy as per Rubin's, ${ }^{1}$ (1911) Criteria i.e., 1). Cervical glands must be opposite the placental attachment. 2). Placental attachment to the cervix must be situated below the entrance of the uterine vessels or below the peritoneal reflection of the anterior and posterior surfaces of the uterus. 3). Fetal elements must be absent from the corpus uteri.

DISCUSSION: Cervical pregnancy is defined as implantation and development of the fertilized ovum within the cervical structure without involving the Corpus uteri. ${ }^{2}$ The incidence of cervical pregnancy is $1: 1,000-95,000$. This rare ectopic gestation has been reported in the literature infrequently. In addition to previous pelvic pathology, iatrogenic interventions can be possible predisposing factors in this type of pregnancy. The association of cervical pregnancy and induced abortion, with traumatic curettage damaging the endometrium, leaving it unsuitable for implantation, is well documented. Occurrence has also been reported due to reimplantation of embryo after abortion. ${ }^{3}$ Partial or complete obliteration of the uterine cavity by intrauterine adhesions might be an important cause of cervical pregnancy. The presence of an IUD and the administration of hormonal therapy for the treatment of Asherman's syndrome might contribute to occurrence of cervical pregnancy.

Presentation of this potentially life threatening condition can pose a diagnostic dilemma to the clinician especially if patient presents late with severe obstetric Hemorrhage. Although Ultrasound examination has been found to be fairly accurate in diagnosing cervical gestation, knowledge of differential diagnosis is a must to deal with a patient in hemorrhagic shock. Inevitable abortion in cervical phase and Caesarean scar pregnancy are the closest confounders, while sometimes squamous cell carcinoma of cervix and gestational choriocarcinoma, ${ }^{4}$ of cervix can also present in similar manner. In our patient, the fetus was implanted below the previous cesarean section scar. The Uterus was empty and Cervix was ballooned up on ultrasound exam and there was no sliding of the products of conception upon applying pressure with the ultrasound probe. Color Doppler also confirmed blood flow around the cervical mass. Unlike true cervical pregnancy, cervical abortion is suggested by the body of the uterus being larger than in the non-gravid state owing to the recent loss of the intrauterine sac. Patients with cervical pregnancy classically present with painless first trimester vaginal bleeding, unlike our patient who presented late at around 13 weeks. Paalman and McElin, 5 in 1959 proposed five more clinically practical criteria which includes:

\section{Uterine Bleeding without Cramping Pain following a Period of Amenorrhea:}

a. A soft, enlarged cervix equal to or larger than the fundus

b. Products of conception entirely confined within and firmly attached to the endocervix

c. A closed internal cervical os and

d. A partially opened external cervical os. Most of the criteria were seen fulfilled in our cases. 
In the recent past, various conservative regimens for the treatment of cervical pregnancy have been introduced to preserve fertility in young women. Various reports have suggested safety of such management particularly with Methotrexate, ${ }^{6}$ embolization of Uterine vessels, ${ }^{7,8}$ or Shirodkar cervical cerclage, ${ }^{9}$ followed by dilatation and curettage. Hemodynamic stability is however a prerequisite for undertaking one of the conservative modes of therapy.

In the majority of cases reported in the literature, particularly those which had progressed beyond 8 weeks gestation, similar to our case, the ultimate method of controlling the bleeding was by means of abdominal hysterectomy. A review states that almost $100 \%$ cervical pregnancies progressed beyond 12 weeks, will eventually require hysterectomy.

CONCLUSION: Cervical pregnancy is a rare condition that can be life threatening if not diagnosed and treated early during the course of pregnancy. Increasing trend of cesarean sections, prior uterine curettage, use of intrauterine device and in vitro fertilization seems to contribute to a rising incidence of cervical pregnancies in recent past. Hence it is essential that clinicians handling emergency obstetric units should include this entity in the differential diagnosis of women presenting with heavy vaginal bleeding early in pregnancy, as early diagnosis and management can play a role in preserving patient's fertility and obviating the need of hysterectomy.

\section{REFERENCES:}

1. Rubin IC. Cervical pregnancy. Surg Gynecol Obstet. 1911; 13: 625.

2. STUDDIFORD, W. E, Cervical pregnancy. American Journal of Obstetrics and Gynecology, 1969,105, 282.

3. Pizzoferrato AC (1), Legendre G, Demaria F, Benifla JL, Cervical pregnancy: a rare case of reimplantation after abortion. A case Report, J Gynecol Obstet Biol Reprod (Paris). 2012 Oct; 41(6): 587-90.

4. Mitrovic SLj(1), Arsenijevic PS(2), Kljakic D(3), Djuric JM(3), Milosavljev Gestational choriocarcinoma of the cervix. Arch Iran Med. 2014 Nov; 17(11): 783-5. doi: 0141711/AIM. 0014.

5. Paalman RJ, McElin TW. Cervical pregnancy; review of the literature and presentation of cases. Am J Obstet Gynecol. 1959; 77: 1261-70.

6. Jurkovic D (1), Hacket E, Campbell S. Diagnosis and treatment of early cervical pregnancy: a review and a report of two cases treated conservatively. Ultrasound Obstet Gynecol. 1996 Dec; 8(6): 373-80.

7. Headley A. Management of cervical ectopic pregnancy with uterine artery embolization: a case report. J Reprod Med. 2014 Jul-Aug; 59(7-8): 425-8.

8. Ryu KY, Kim SR, Cho SH, Song SY. Preoperative uterine artery embolization and evacuation in the management of cervical pregnancy: report of two cases. J Korean Med Sci. 2001 Dec; 16(6): 801-4. PubMed PMID: 11748367; PubMed Central PMCID: PMC3054791.

9. Mashiach S, Admon D, Oelsner G, Paz B, Achiron R, Zalel Y. Cervical Shirodkar cerclage may be the treatment modality of choice for cervical pregnancy. Hum Reprod. 2002 Feb; 17(2): 493-6. PubMed PMID: 11821302. PMC3054791. 


\section{CASE REPORT}

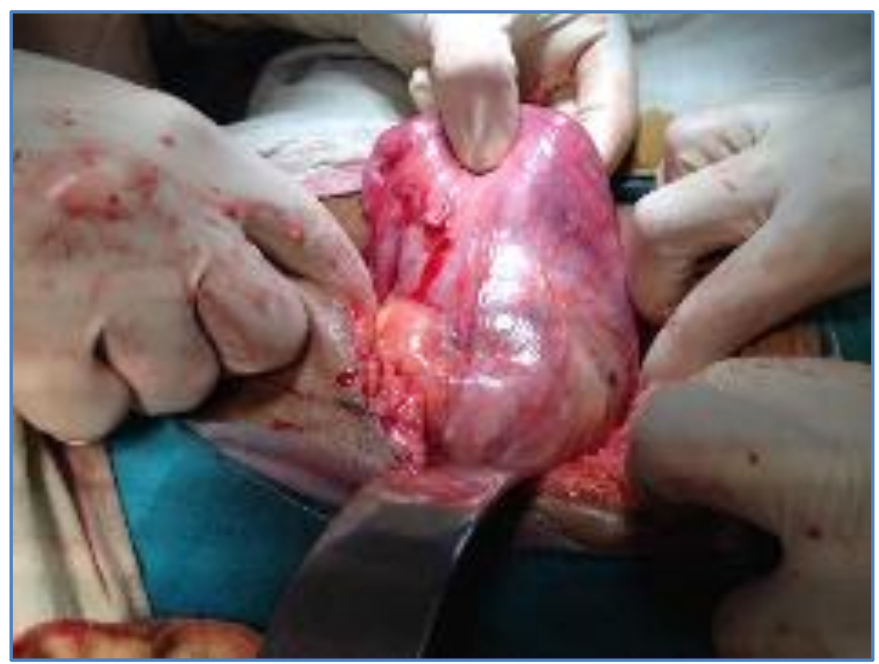

Intraoperative image showing "Hourglass shaped Uterus " with enlarged Cervix

\section{AUTHORS:}

1. Bhakti Gurjar

2. Mansi Shrigiriwar

3. Kshama Kedar

\section{PARTICULARS OF CONTRIBUTORS:}

1. Assistant Professor, Department of Obstetrics and Gynaecology, Indira Gandhi Government Medical College, Nagpur.

2. Associate Professor, Department of Obstetrics and Gynaecology, Government Medical College, Nagpur.

\section{FINANCIAL OR OTHER}

COMPETING INTERESTS: None
3. Associate Professor, Department of Obstetrics and Gynaecology, Indira Gandhi Government Medical College, Nagpur.

\section{NAME ADDRESS EMAIL ID OF THE} CORRESPONDING AUTHOR:

Dr. Bhakti Gurjar

\# 702, Raviram Residency, 13-Chitale Marg, Dhantoli, Nagpur.

E-mail: drbhaktigurjar@ymail.com

Date of Submission: 13/08/2015. Date of Peer Review: 14/08/2015. Date of Acceptance: 02/09/2015. Date of Publishing: 07/09/2015. 